\title{
Leveraging Local Competitiveness
}

\section{Leveraging Local Resources}

How do SMEs, competing for global export markets, remain competitive when operating, to a large extent, from Switzerland, one of the world's most expensive countries? Data compiled annually by the IMD World Competitive Report document that the cost of a single hour of labor in Switzerland is one of the highest in the world, while at the same time productivity per hour is also one of the highest, partially mitigating any cost disadvantage. Ricola, the herbal candy maker, serves as an example of a highly automated production practice that many companies have adopted.

Ricola remained attached to its location in Laufen where the entire production took place. Production was organized into two long shifts with most of the employees recruited locally. The efficiency of the production operation, including the use of automation and robots allowed the company to compensate for otherwise higher salary costs compared to neighboring countries. Although Ricola acquired its equipment from external suppliers, the extraction method and tying each step into a continuous flow were proprietary and developed internally. In 2019, Ricola produced 7 billion drops a year. ${ }^{1}$

The sharp appreciation of the Swiss Franc versus the Euro and the USD over the past few years created an additional, and particular, problem for Swiss exporting SMEs. At some companies, the exchange rate disadvantage was alleviated by production staff offering to work more hours than they were compensated for on a temporary basis; other companies decided to shift material sourcing to the Euro area; as a last resort, other firms moved some low-skilled, but labor-intensive, production steps abroad. This process has been described in greater detail in an earlier chapter. Here, Mikrop serves as an example of the latter strategy.

\footnotetext{
${ }^{1}$ Adapted from Ricola company profile. 


\begin{abstract}
Mikrop regarded the relatively high cost of conducting business in Switzerland as a disadvantage. Labor and construction cost, for example, were significantly higher than in other European countries. In addition, Mikrop was hard hit by the 'Swiss Franc shock' since 2008. That extraordinary phase of appreciation of the Swiss currency posed a serious challenge to companies which produced primarily in Switzerland, and they could only benefit to a limited extent from cheaper purchasing prices abroad. To counter the high cost pressure in Switzerland, Mikrop outsourced part of its production to Serbia. This strategy was reserved for the production of standardized, basic products. ${ }^{2}$
\end{abstract}

Overall, Mikrop regarded the framework conditions in Switzerland as very conducive to the development of the company. The high quality of the education system, relatively low and transparent taxes, political stability, and government efficiency were considered major advantages. These positive framework conditions also facilitated attracting talent from abroad.

The high-cost environment, in combination with the shifts in exchange rates for the Swiss currency, put FISBA's profit margin under pressure in recent years. Consequently, the company considered shifting some of its production facilities abroad, but ultimately decided against this move. The general assessment was that, despite a rising administrative burden and high production costs, Switzerland still offered sufficiently competitive framework conditions.

Confronted with the same challenges concerning currency appreciation, Medartis management adopted a more accepting view.

At Medartis, excellence in engineering and software programming guaranteed top quality and efficiency. Concerning the upward valuation of the Swiss Franc vs. the Euro or USD, the company believed it 'just will have to deal with it' and would not consider moving parts of the operation elsewhere. ${ }^{3}$

For maxon, labor wages were not the only basis on which to make cost comparisons. Using another metric put a different spin on the cost comparison game even when labor costs might be much lower elsewhere.

maxon's growing business in Korea led to the creation of a production unit there as well. Growing out of a successful distribution business, the Korean operation began with producing brushless motors with iron core winding, because winding around iron was easier to accomplish. Later, a robotics operation for iron cores was added in 2013. On a comparative basis, labor costs in Korea were about one quarter of the Swiss level. Despite the wage level differences, the Swiss operation was still competitive on the basis of profit-per-person, the key operating metric used at maxon. The indirect costs at the Swiss operation were about two thirds, with one third for direct production. However, a shift was taking place there as well. ${ }^{4}$

The previous sections of this book covered a range of decisions and actions, typical of Swiss SMEs, that contributed to long-term and sustainable strategies.

\footnotetext{
${ }^{2}$ Adapted from Mikrop company profile.

${ }^{3}$ Adapted from Medartis company profile.

${ }^{4}$ Adapted from maxon company profile.
} 
There were a number of additional practices that Swiss SMEs engaged in to help mitigate the cost disadvantage which are well worth reflecting on. This section will put the spotlight on some of those strategies that struck the research team as particularly noteworthy.

\section{Engaging in Premium Pricing}

With a Swiss and therefore invariably a high-cost base, premium pricing is a practice followed by many of the Swiss SMEs simply because the full high-cost burden cannot be absorbed through superior operating efficiency. For some companies, the price differential compared to non-Swiss competitors can be substantial.

- Felco, producer of pruning shears, retailed its best-selling, Model 2, for CHF 50 in Switzerland, compared to Asian competitors who were retailing similarlooking products for one-third of the Felco price.

- Caran d'Ache priced its writing instruments at about 20 to 25 percent above their major competitors.

Despite these considerable price differences, both Felco and Caran d'Ache thrived over a long period of time. Management at both companies has learned to argue the value of the products, in addition to how, and why, their quality can justify such considerable price differences.

For Caran d'Ache, perfection in its products allowed it to issue a lifetime guarantee for its writing instruments. It combined sustainability processes with superior quality and was able to list quality along a number of dimensions. Its built-in 'air bags' worked as shock absorbers for pencils when dropped. The pencil sets in boxes could be refilled with single pencils and the pencil boxes could be reused for other purposes. The company used twice as much gold as competitors to plate and emboss its pens and offered repairs or refills. All of these elements contributed to lowering the life-time cost to the user while adding superior functionality and durability. ${ }^{5}$

For Felco, competing at times with prices three times higher than those of low-price competitors meant being able to articulate a justification for the premium price. In Felco's case, this was primarily taking a longer view-providing a product that clients could use over many years and, in effect, amortizing the cost for the consumer over a lifetime and therefore lowering it.

Felco products had to meet the highest quality standard. Three factors were the basis of this superiority: ergonomics, parts inter-changeability and durability. On all three counts, Felco argued, its products were superior to competing makes. Ergonomics was critical from the users' point of view. In vineyards, plants had to be pruned during a limited time window, with professional pruners in large vineyards performing thousands of cuts a day. Felco

\footnotetext{
${ }^{5}$ Adapted from Caran d'Ache company profile.
} 
pruning tools could withstand 10,000 cuts a day without causing injury to the user's hand. Comfort for the pruner's hand, as well as minimum weight, and a spring that resulted in effort reduction, were critical.

Felco's principle of inter-changeability resulted in a modular design where individual components were replaceable and could easily be changed when worn out. Interchangeability over a long service life of pruners could only be achieved if production was of high precision that assured identical parts, even if produced years apart.

Durability was a requirement for long-term use. Felco products were made to last, to be passed on from generation to generation rather than treated as a tool with an expiration date. To achieve durability, and to allow the company to issue a life-long guarantee, only the most exacting manufacturing processes and materials could be used. The best possible pruning products included precision in pruning which also guaranteed "quick healing of the pruning wound," eventually resulting in higher yields for the farmers. ${ }^{6}$

Both Felco and Caran d'Ache developed elaborate argument threads to change customers' inclination to compare initial acquisition cost and consider the long-term running cost instead, or alternatively the long-term ownership cost. What might appear to be a premium price when comparing initial purchase prices was, in fact, considerably below those of the cheaper, competitive models when the long-term ownership cost for the products was taken into consideration.

Fraisa, maker of cutting tools, was confronted with lower-cost imports from Asia. It responded by creating a tool service, described earlier, which had also an impact on the ownership costs of its tools, compensating for an otherwise high up-front acquisition cost:

Fraisa entered into the tool refurbishing business as a major break from the reseller model. If professionally done, refurbished tools could be used two or three times before the end of tool life. Fraisa established special collection boxes for used tools on customer premises and provided a pick-up service by its own trucks. ${ }^{7}$

Pilatus, producer of private planes, was operating at the opposite spectrum of unit pricing with its executive jets priced at several million Swiss Francs. Its argument that the PC-12 was a low-cost choice over the long run, included the resale value of its planes, as well as an aircraft layout that reduced time and costs for maintenance.

Certified for single pilot operation, the Pilatus PC-12 became the plane of choice for ownerflown executive pilots. Due to its versatility, it could be used for passenger operations, as an air ambulance, for cargo transport, or for special government missions. Strong demand came from the US where most planes were delivered in executive configurations. The price of the PC-12 had risen over time with improvements and reached about USD 5 million (2017). This price was competitive due to its reliability and the fact that the resale value of PC-12

\footnotetext{
${ }^{6}$ Adapted from Felco company profile.

${ }^{7}$ Adapted from Fraisa company profile.
} 
models retained a higher level compared to competing models. The PC-12 engine layout was designed for ease of maintenance and for other key parts to be easily replaced and accessible for mechanics. ${ }^{8}$

Throughout our interviews, Swiss SMEs consistently mentioned that maintaining superior quality standards was a key ingredient to their success. Quality as a competitive element requires the ability to painstakingly document it, make it tangible to customers, and surpass competing offers. At times, this takes the form of a long service life, superior precision, exceptional workmanship, or simply in terms of the fact that the product really works! Superior quality is a key element to justify a price premium. Stringent quality control was widely employed, regardless of whether part, or all, of the production was offshored.

When Mikrop established a subsidiary in Serbia in 2007, the company had been able to transfer specific technical knowledge in optics production, with the effect that many processing steps of production took place in parallel in Serbia. This allowed Mikrop to offer attractive pricing in line with market expectations. Review and final inspection were always done at Mikrop's main production site in Switzerland, thus guaranteeing the high Swiss quality standards customers had come to esteem. ${ }^{9}$

As a small player in the field of metrology, Sylvac benefited from its singular focus on measurement tools and devices in order to compete against larger, lowerpriced competitors from China and Japan.

Sylvac leveraged its measurement accuracy and IoT connectivity. Reliability as perceived by the end user was critical. Users had to rely on the results of their measurements, which required trust. ${ }^{10}$

FISBA, in optics, used its emphasis on quality to deter larger players from entering the market space.

FISBA's production expertise combined with its focus on quality leadership, as well as its focus on securing a niche, led to the company's strong market position and created certain entry barriers for possible new entrants. For bigger players, the market was relatively small compared to the investments needed to provide high quality products; and, for smaller players, the high costs to enter that market were often prohibitive. ${ }^{11}$

As demonstrated by Caran d'Ache, the use of a sustainability strategy could also be used as a differentiator to add support for a price premium.

Caran d'Ache also wanted to differentiate itself through its sustainability strategy, that, while adding costs to the production, were of value to end-users and society at large. The

\footnotetext{
${ }^{8}$ Adapted from Pilatus company profile.

${ }^{9}$ Adapted from Mikrop company profile.

${ }^{10}$ Adapted from Sylvac company profile.

${ }^{11}$ Adapted from FISBA company profile.
} 
wood dust from its cedar wood production was collected and used to heat the factory. Water-based varnishes on the pencils took longer time to dry while the competition was still working with solvent-based materials. The wood used for its pencils come from strictly managed forests. Throughout its manufacturing processes, Caran d'Ache took exceptional care to use healthy materials. Caran d'Ache received recognition for its quality processes and sustainability efforts from a number of certifications agencies. Its environmental management was certified by ISO $14001 .^{12}$

In general, Swiss SMEs found ways to combat the impact of a high sticker price by softening its impact through a number of strategies to enhance value-in-use, in effect lowering the customers' long-term cost-in-use. At times, this long-term cost even went below the competitive offers that came on the market that had a lower sticker price and inferior performance.

\section{Leveraging Core Competencies and Skills}

The principle of a firm's core competence as a source of competitive advantage has been an often-cited concept in management theory. Its proponents describe it as "a harmonized combination of multiple resources and skills that distinguish a firm in the marketplace." ${ }^{\prime 13}$ The practices of Swiss SMEs reflected this principle, and many companies leveraged this idea to achieve a competitive advantage, although it may take different forms.

Acutronic built its entire value chain around its core competencies of engineering, electronic, and assembly, while leaving other, noncore, activities to partners or outsourcing them.

The core competency of Acutronic was the development, design and assembly of precision motion simulators. The company still built its own power amplifiers and controlling-related technical parts in-house, because there were no products on the market that satisfied the company's needs. Control loops and engineering know-how was crucial, due to the high accuracy requirements in the industry. Despite the fact that most other parts used for Acutronic's products could be bought off the shelf, it was very hard to reach the accuracy and performance of the company's products. On the other hand, the company's focus on its core competencies led to the outsourcing of most of the production activities. The company sourced a big portion of all non-critical parts from external suppliers and focused on its engineering and electronics, as well as assembly competencies. By doing so, costs were kept low and the company was able to stay competitive. Because of efficient processes, the costs per unit at Acutronic were still comparable with competitors in other countries, despite the high labor costs in Switzerland. ${ }^{14}$

\footnotetext{
${ }^{12}$ Adapted from Caran d'Ache company profile.

${ }^{13}$ Prahalad C, Hamel G (1990) The core competence of the corporation. Harvard Business Review 68(3): 79-91.

${ }^{14}$ Adapted from Acutronic company profile.
} 
For core competencies to be of competitive value, they have to be honed and constantly reinforced. One of the most extreme examples of this was found at Caran d'Ache where the competencies were broken down into many steps, supported by its own equipment and which covered many different trade skills and raw materials.

Carole Hübscher, Chairwoman of the Board of Directors, likened the Caran d'Ache manufacturing process for graphite "dough" for pencil cores to "cooking, similar to pasta or baking bread." It involved 35 different steps and the company owned about 800 different pieces of manufacturing equipment, many designed by the company itself. An inventory of skills determined that Caran d'Ache staff exhibited about 90 different skills, ranging from lead dough preparation to lead manufacturing, to the management of colors for pencils, as well as covering knowledge about different materials, from metal to plastic and wood. Base skills required originated from chemistry, mechanics, wood working and lacquering. ${ }^{15}$

Sometimes, the core competencies arrive with the skills of the company founder. This was the case at Kuhn Rikon, producer of pans and cooking utensils, where the founder's competency had previously been acquired in the French mining industry; this experience became key to the company's founder navigating change in the industry.

Kuhn Rikon founder Heinrich Kuhn soon realized that the rapid change from wood fired to electric stoves would require different kind of pans. On a wood stove, the shape of the bottom did not matter. With the emergence of electric stoves, absolute flatness of the pan's bottom was essential. As an engineer, Kuhn knew how to roll flat walls from aluminum sheets. Aluminum, then still a new metal, also provided excellent heat conductivity essential for electric hot plates. ${ }^{16}$

Although most companies did not formally communicate their core competencies to the public, there was one instance at Ricola where the company found that demonstrating its core competence as "herbal competence" added greatly to its credibility with the general public and its consumer base.

Demonstrating its herbal competence, Ricola created five herb gardens in the Swiss mountain area to show the 13 central herbs to the public. By the early 1980s, the success of Ricola sales began to outstrip its supply of herbs, which up to that time came mostly from the local area. The company connected with over 100 contract herbal farmers in the Swiss Jura and mountains, encouraging them to plant the herbs on contract. Ricola provided the seeds to farmers. The total plantation area amounted to an equivalent of about 124 football fields and yielded 1400 tons of fresh herbs each year. Herbs were dried immediately in the various mountain regions, then put in bags and shipped to the Ricola herb center for further sorting, drying, cleaning and mixing with other ingredients.

The Ricola herb center was a large, dedicated facility where a number of herb processing steps took place. From the dried herbs, natural essences were extracted and mixed with other ingredients. This mixture was then cooked and molded into drops and pearls and left to cool. Processing the dried herbs to create the 13-herb base mix was seasonal and extended over

\footnotetext{
${ }^{15}$ Adapted from Caran d'Ache company profile.

${ }^{16}$ Adapted from Kuhn Rikon company profile.
} 
only three to four months. To assure a continuing flow for further production, the company stored herbal extracts for several months. Each year, Ricola processed about 250 tons of dried herbs. ${ }^{17}$

Core competencies are also shaped over time and can develop gradually. An excellent example of accumulating such skills that then grow into a core competence is provided by Pilatus, the general aviation aircraft builder. Its present competence evolved over more than 60 years.

Pilatus' evolution from a maintenance role into assembling and subcontracting parts to become a full-fledged developer and builder of competitive training or civil aviation planes, including jets, did not happen overnight. At each step, the company gained valuable experience which was added to earlier steps. Over time, Pilatus had accumulated the complete experience needed to become an airplane designer and building company.

The ruggedness of its earlier training models was carried over into its civil aviation models. Experience with maintenance was capitalized by building planes for easy maintenance. The need to provide multiple variations of the same model series led to experience with modularization. The experience with STOL in the PC-6, its first civil aircraft, was rolled over into its PC-12 and PC-24 executive airplanes, allowing for the utilization of thousands of small and ill-equipped civil airports in rural regions. ${ }^{18}$

Core competencies are not acquired from one day to the next or as a result of a single invention or innovation. They are accrued over time, often over years or decades. For most of the researched SMEs, these competencies became an essential element of their winning practices as they competed for global markets.

\section{Leveraging Talent}

In a country where unemployment is traditionally low and where industry relies to a considerable degree on employing staff from mostly European and neighboring countries, the scramble for talent was a recurring theme in the company interviews. Attracting the right workforce was a particular challenge for those companies located outside major urban centers, where the majority of the SMEs in the sample were headquartered. To alleviate a constant shortage of qualified employees, companies employed various strategies to attract talent, but more often invested a considerable amount of resources to grow talent in-house.

\footnotetext{
${ }^{17}$ Adapted from Ricola company profile.

${ }^{18}$ Adapted from Pilatus company profile.
} 


\section{Recruiting Talent in Urban Centers}

The challenges for attracting talent faced by SMEs differed to a considerable degree by their location and to the extent that the urban centers could provide the required skill set. Both Medartis and Bachem benefited from the richness of the Basel region for health and life sciences talent, as well as the closeness to Germany and France. However, the two companies employed different strategies when it came to tapping into the cross-border talent pool.

Medartis with its operation in Basel could tap into the regional supply of top talent for mechanical engineering and software development. Their commitment is exceptional. This talent would not be transferable to China (Miesch, CEO).

Despite its closeness to the German and French borders, the company employed few border commuters in its operation. When it came to staff its managerial and governance positions, Medartis could select from a pool of former executives with sound experience gained at Stratec/Synthes medical implant operations, as well as from the US firm Stryker, and Straumann Dental. ${ }^{19}$

Bachem found the necessary talent for its main operation in Bubendorf by competing with large Pharma companies in the greater Basel region. The competition for talent led to higher salaries at Pharma companies, often forcing Bachem to recruit its workforce across the border from Germany. Some 40 percent of the Bubendorf workforce were German nationals, and of those half commuted daily across the border. Given the scientific nature of the Bachem business and its industry, the company executive committee was dominated by executives with strong academic credentials and strong experience in the life sciences industry. ${ }^{20}$

A contrasting experience was offered by Caran d'Ache finding itself in the midst of a large urban center, Geneva, but in need of some very specific skills and talents that were not necessarily in ample supply.

For Caran d'Ache, with about two thirds of its staff involved in production, finding the right talent was important. In the Geneva region, there was access to talent steeped in manufacturing around metal, such as for the watchmaking. But for many of the Caran d'Ache processes, staff had to be trained in-house with retention being an important consideration. On average, employees had been with the company about 15 years, with some as long as 40 to 50 years. Although the company participated in apprenticeship programs, for core manufacturing processes only in-house training would suffice as there were no other employers with similar needs in the region. ${ }^{21}$

\footnotetext{
${ }^{19}$ Adapted from Medartis company profile.

${ }^{20}$ Adapted from Bachem company profile.

${ }^{21}$ Adapted from Caran d'Ache company profile.
} 


\section{Recruiting Talent to Rural Areas}

For those SMEs that were larger than average and located in rural areas, the challenge was to convince prospective staff to make the move, either through a daily commute or to relocate closer to the company altogether. Success at expanding their recruiting radius beyond their local region determined much of their ability to attract staff.

With Thermoplan's growing operations concentrated on a single campus with several adjacent buildings in Weggis on Lake Lucerne, attracting suitable talent was an important role for top management. For engineering and development positions, Thermoplan relied on its relationships with regional universities of applied sciences, as well as with universities such as ETH Zurich. Weggis was not served by a rail connection, and employees were either using local bus services to get there or, in most cases, used their private cars. This tended to affect the recruiting radius for talent. ${ }^{22}$

For its talent recruiting, Komax undertook considerable efforts to recruit employees on a regional basis. Access to private or public transportation helped attract employees beyond the local region and Komax could tap into the market for talent in the Cantons of Zurich, Zug or Aargau. The company found that being the market leader and experiencing considerable growth was an important aspect to attract employees. For many areas, employees with a combination of technical and commercial or business background were of particular interest to Komax, such as managerial talent who had earned an EMBA on top of initial technical qualifications. $^{23}$

maxon, with its operation based in Sachseln in central Switzerland, attracting the right and sufficient talent for the company was a major concern for top management. Aside from recruiting from its internal apprenticeship program for production staff, development and research talent were recruited from the leading Swiss engineering schools. With expanding volume, the business unit for mechatronics and dental applications were concentrated in Sexau, Germany. The mentality in the Schwarzwald region of Southern Germany is similar to Switzerland, making collaboration and integration of operations easier (Eugen Elmiger, CEO). ${ }^{24}$

The examples of Thermoplan, Komax, and maxon demonstrate that a big factor in attracting talent away from urban to regional centers was the ease of commuting. The ability to access good public transportation to travel to the company locations was important; this put the firms in remote areas, and hence further away from the urban centers, at a disadvantage.

Smaller SMEs located in rural areas were the most adversely affected in the hunt for talent. They could, however, be the most successful if they concentrated on hiring regionally, seeking employees who lived locally and actually preferred to work close to home. Both DC Swiss, maker of threading tools, and Wyon, producer of rechargeable batteries, were examples for companies which played this card.

\footnotetext{
${ }^{22}$ Adapted from Thermoplan company profile.

${ }^{23}$ Adapted from Komax company profile.

${ }^{24}$ Adapted from maxon company profile.
} 
DC Swiss, located in the small town of Malleray in the Jura part of the Canton Berne, recruited its talent from the region, including the cities of Biel/Bienne and Delémont. The manufacturing skill required was 'grinding', and even a trained machine operator needed three to six months to master it. Hiring was by word of mouth and staff turnover was relatively low. There was always a risk of losing good staff to major manufacturers who would recruit young staff away from DC Swiss at significantly higher salaries. The company did not actively hire workers from across the Swiss border, as those employees were viewed as not having the same work culture as the Swiss. ${ }^{25}$

Wyon, located in a small town in Appenzell, made the best of its rural location by concentrating on the recruitment of highly talented staff who appreciated a rural lifestyle and working close to home and family.

For Wyon, starting up production, and growing the company and its leadership team, presented a special challenge, especially in a rural place like Appenzell. Because of their special requirements, Wyon had to train people for quite some time. Wyon was looking for people who had at least completed an apprenticeship in a related area. The reason for this was Wyon's strong focus on quality and its belief in the higher reliability of qualified personnel. Wyon employed staff with diverse backgrounds, from poly-mechanics to electrical engineers, aeronautical engineers, chemists, automation engineers and software engineers. So far, filling an open position had not been a problem. There were many people in the Appenzell with a good education who were not able to find a job there. The people from Appenzell felt close to their region and wanted to work not far from where they lived. Wyon enjoyed a good reputation in the area and rarely advertised for a production employee. Simply spreading the word within the company led to enough suitable applications. Fluctuation was also low. Most employees came from the local region and a large part of the staff even went home for lunch, as was common practice in rural Switzerland. However, at some point Wyon might reach a critical size and may need to recruit more people from outside. ${ }^{26}$

How far a company can go to find suitable staff and how improved public transport to rural operations can improve hiring are illustrated by Kuhn Rikon.

When Kuhn Rikon experienced difficulties hiring production workers in the early 1960s, the company simply built factory housing next to it. However, even that did not alleviate the recruiting bottleneck. When a large group of Tibetan refugees arrived in Switzerland around that time, the company offered its housing and successfully managed to recruit among them, and even assisted with building a Tibetan monastery in the area. Today, some 14 different nationalities are represented among its workforce, including descendants of the initial Tibetan refugees. More recently, talent hiring was alleviated by the opening of a new S-Bahn (suburban railway) connecting Rikon via a direct line to Zurich Main Station. ${ }^{27}$

\footnotetext{
${ }^{25}$ Adapted from DC Swiss company profile.

${ }^{26}$ Adapted from Wyon company profile.

${ }^{27}$ Adapted from Kuhn Rikon company profile.
} 


\section{Growing Talent Internally}

Common to all SMEs was the special emphasis on growing their own talent, particularly through participation in the apprentice system. Sometimes referred to as a dual system, combining practical training with part-time schooling, the apprentice system was particularly well represented in Switzerland. The number of students finishing their education with a Certificate of Maturity, or equivalent to the German Abitur, was at about 30 percent of graduates, a very low proportion compared to other $\mathrm{OECD}^{28}$ countries. Below is a selective list of companies and their engagement in apprenticeship programs.

- Sefar trained its own apprentices in weaving because only few apprenticeship programs were left.

- Thermoplan maintained 14 apprentices in its Weggis operation for a variety of professions.

- EAO was a firm believer in the dual systems and offered apprenticeships in 18 different sectors.

- Acutronic participated in apprenticeship programs to train its own future workforce.

- Caran d'Ache participated in apprenticeship programs including for core manufacturing processes.

- Sylvac offered several apprenticeships in collaboration with other local firms.

- Komax had almost 50 apprentices in training in Switzerland with another 25 in Germany, where the dual system was also popular.

- FISBA invested heavily in the development of apprentices to replenish the pool of skilled employees, with 29 apprentices out of a staff of 350 .

- maxon engaged about 50 apprentices in its Swiss factory.

- Pilatus enhanced its highly skilled workforce through an extensive apprenticeship program with more than 130 apprentices in many different fields training within the company.

The diversity of the companies mentioned, in terms of size, industry, and location, speaks to the pervasive support of the apprenticeship system among Swiss SMEs. That the larger companies can, and do, commit larger resources to this is easily understood. The reason for undertaking this effort, however, also lies in the understanding that such a practice will train the talent of the future and that without such an undertaking, the supply of skilled employees might shrink.

- Komax offered apprenticeships in polymechanics, engineering design, automation, and commercial areas. It was important for Komax to be able to hold on to promising staff members once they completed their apprenticeship.

\footnotetext{
${ }^{28}$ Organisation for Economic Co-operation and Development.
} 
- For maxon, as an operation based in Sachseln in central Switzerland, attracting the right and sufficient talent for the company was a major concern of top management. It engaged in an extensive apprenticeship program with about 50 apprentices enrolled at any time. The company was considering expanding to up to 100 apprentices, which would mean an expansion of the geographic range and the need to build a residence, similar to a university dormitory, so that apprentices can stay during the week, significantly increasing the recruiting radius.

- Pilatus, the largest company in our sample-with 2000 employees in Switzerland, it is also the largest employer-had more than 130 apprentices on its site and offered three- or four-year programs in a multitude of professions, such as sheet metal mechanics, electricians, lettering designers, IT specialists, production mechanics, and polymechanics. Since 1942, when the company began with apprenticeships, some 1300 apprentices graduated from its programs and about one-third of them stayed on to become employees. Programs were also offered to students of ETH Zurich who had to complete a six-week practical internship as part of their degrees and for engineering students who could complete eight of the 12 months of practical experience at Pilatus required for their degree.

DC Swiss, a smaller company, was a relatively big player in the apprenticeship game. To be both more effective, and to offer a more attractive program, the company joined up with other firms in the region, including Sylvac, which is described below.

For DC Swiss, an important aspect of talent management was the participation in apprenticeship programs. The company employed about 15 apprentices for three- to five-year apprenticeships. An important feature was the polymechanic apprenticeships offered in conjunction with several other local firms that resulted in a broader training than one offered by a single firm only. Apprentices were rotated among five other participating firms. These apprenticeships were for young people, after completing the required nine years of education, interested in joining the DC apprenticeship programs. ${ }^{29}$

The impact of regional cooperation and the benefit of a cluster of similar technologies were also exploited by FISBA and other firms, both for regular talent and for apprentices in particular.

Recruiting adequately trained employees for its operations was one of the principal challenges faced by FISBA. However, thanks to the collaboration with other optics manufacturers in the region, there was a pool of talents in Eastern Switzerland. All these companies were located around St. Gallen and the Rhine Valley and they were training their own apprentices in precision optics. Upon completion of their apprenticeship, some of those highly qualified workers would often remain in the company while others would join another optics manufacturer in the region. Over the years, FISBA recruited and built talent via the

\footnotetext{
${ }^{29}$ Adapted from DC Swiss company profile.
} 
apprenticeship scheme and in-house training, and from universities and technical colleges, both in Switzerland and in neighbouring Germany. FISBA invested heavily in the development of apprentices to replenish its pool of skilled employees. Not surprisingly, 29 of FISBA's 350 staff were apprentices. In addition, the company invested in its workforce by encouraging ongoing education and training at technical institutes. The most promising employees could then become experts in optics design and photonics. ${ }^{30}$

At some companies, the training of skilled staff went beyond young apprentices. Scarcity of talent encouraged some firms to pursue nontraditional paths to upgrade its workforce. maxon began to enroll some of its lower-skilled female workforce into its technical apprenticeship programs to upgrade their skills. Fraisa, the milling toolmaker, offered such a formal apprenticeship program to long-serving production staff who had never been given a chance to obtain a formal certification when they entered the workforce.

Fraisa maintained an active apprenticeship program for manufacturing jobs. Of equal importance was the extension and enhancement of qualification of its older workforce, many of those had not completed a apprenticeship and yet were valuable members of the company. The experience of lesser qualified members of the workforce searching for new jobs during the financial crisis led Fraisa to adopt a widely recognized apprenticeship program for non-skilled workers. Since 2012, 22 production employees graduated from the program with a Federal Diploma equivalent to that offered for younger staff in regular apprenticeship programs, with half of them 50 years and older. This program allowed previously less qualified workers to keep up with the requirements of Industry 4.0 and IoT developments on the shop floor. ${ }^{31}$

\section{Apprenticed Managers}

The support of the Swiss apprenticeship program, or dual educational system, has a long tradition. Apprenticeships can also be a steppingstone to future executive positions as the examples of many of the current SME leaders demonstrate. Many of these apprenticed managers followed up their initial training with degrees from either Swiss technical schools or universities, or with a degree in business from a number of executive MBA programs available in Switzerland. The following are a few examples (not complete) from the interviews.

- Eugen Elmiger, CEO of maxon.

- Willy Miesch, CEO, and Thomas Straumann, Chairman, of Medartis.

- Eric Schnyder, CEO of Sylvac.

- Hans Oetiker, founder of Oetiker Group.

- Jean-Pierre Etter, founder of LEM.

- Adrian Steiner, CEO of Thermoplan.

- Peter Grogg, founder of Bachem.

\footnotetext{
${ }^{30}$ Adapted from FISBA company profile.

${ }^{31}$ Adapted from Fraisa company profile.
} 
The careers of these company founders and top executives are living proof that stepping into an apprenticeship is not a dead-end street; it can be a first step toward a business career. These leaders, due to the nature of their training and skills, are very close to the technical aspects of their companies and are one of the reasons for the practical orientation of Swiss SME management.

\section{Leveraging Institutions of Higher Education}

This section would be incomplete if it did not mention the role played by Swiss universities in the education of talent, as well as their collaboration with companies on special projects. A strong role was played by ETH Zurich and EPF Lausanne, the two federal institutes of technology. Both institutions rank in the top 20 research universities worldwide and the only ones in that group located in non-Englishspeaking countries. ${ }^{32}$ Several of the current leaders of SMEs researched are graduates from either of the two. Furthermore, a large number of the board of directors of the SMEs that went public are also graduates of these two federal institutions.

In 1997, three PhD students at the ETH Zurich, Daniel Ammann, Andreas Thiel, and JeanPierre Wyss, all under the supervision of Professor Gerhard Tröster, Professor for Digital Systems and Wearable Electronics, decided to leave their academic studies to start $\mathbf{u}$-blox for the purpose of developing and marketing electronic modules for producers of communications systems, with early emphasis on miniaturized GPS receiver modules. They left the ETH academic program with an MA Diploma in hand. ${ }^{33}$

Larger Swiss SMEs who maintained more formal research and development staffs often recruited graduates from these two institutions, although not exclusively. And as Eugen Elmiger, CEO of maxon, confided, some of these ETH graduates, upon joining the company, realized how much they had missed out on by not going through an apprenticeship program first, referring to skills that were later difficult to make up for.

A second important source of talent was the Universities of Applied Sciences (UoAS, Fachhochschule) clustered in several regional groupings with campus facilities in various smaller Swiss cities. The UoAS included a range of traditional locations with specialties that remain relevant to this day. Among the campuses mentioned most often were Yverdon, Neuchâtel, Biel, and Le Locle in the Frenchspeaking part of Switzerland, and Burgdorf, Olten, Windisch, Luzern, St. Gallen, and Buchs in German-speaking Cantons. Frequently, companies ran research and development projects in conjunction with these technical universities.

\footnotetext{
32،"QS University Ranking 2020,” ETHZ No. 6; ETHL No. 18.

${ }^{33}$ Adapted from u-blox company profile.
} 
- EAO had executed projects at two regional Universities of Applied Sciences, in Olten, where a large campus existed, and in Windisch, where the plastic molding program was very strong.

- Sylvac often recruited electronic and software developers from the technical programs at HES in Yverdon.

- Mikrop, leveraging the optics and photonics cluster in the region around St. Gallen, had developed a tradition of collaborating in the field of education and training. For example, the companies in the optics cluster jointly developed a study program in optics and worked together on a range of projects with the Institute for Production Metrology, Materials and Optics at the local University of Applied Sciences of Eastern Switzerland.

Rüeger, located not very far from EPFL Lausanne, offered an example about how these technical institutions can be leveraged to generate new technical and business ideas.

\begin{abstract}
Rüeger maintained active contacts with regional technical universities, such as with EPFL Lausanne in the areas of new measuring technologies, as well as HES St. Imier and HES Yverdon, that graduated technical talent of importance to Rüeger. In 2008, Bernard Rüeger, then CEO of Rüeger, managed to acquire a start-up firm connected with EPFL and integrated it later into the Rüeger company. Started in 2003, by an independent inventor who used his experience in the field of deep oil-frying in the fast food industry as the basis for his $\mathrm{PhD}$, he developed a system to measure the quality of frying oil through temperature, intended for deep fry makers. The start-up had difficulty in reaching industrial scale. The market leader in this equipment already had its own solution, but another competitor was looking at a system for integration into its deep-frying equipment. Eventually, Rüeger granted a license for the US market, with sensors made for Europe produced in Crissier. ${ }^{34}$
\end{abstract}

For talent trained in business, the leading university tapped for recruiting was the University of St. Gallen, the source for talent in finance, administration, and marketing. A large number of business leaders and executives in Swiss SMEs, however, went the dual route, starting as apprentices, then got a technical degree from a UoAS, and followed that with a part-time EMBA program offered by regional institutes. Many companies preferred the route of first acquiring technical training and then following that up with a shorter training period in business administration. MBA graduates from international business schools were the exception.

\title{
Leveraging Entrepreneurship Among Employees
}

Employees at Swiss SMEs do not typically assume the roles of owners or managers. However, the example at Selectron shows that under the right conditions, employees can very well step in and, in due course, affect the survival of a company. Prompted by its then owner, the Schneider Group, to find a buyer, Selectron failed to

\footnotetext{
${ }^{34}$ Adapted from Rüeger company profile.
} 
secure a deal. Its CEO, Emmanuel Hannart, then convinced the staff to follow him into an employee buyout with great success.

\begin{abstract}
When the sale to ABB failed, Hannart, Selectron CEO, took another look at the buyout option. Working with business contacts and private investors, he and his advisors put together a package for the employees, not just managers, to buy the company. Schneider agreed to sell at the same price previously negotiated with ABB and to grant more time to put the deal together. Banks, after first balking at the idea of a leveraged employee buyout, agreed to finance about 60 percent of the acquisition price. For the 40 percent equity required, 75 percent was contributed by a group of international investors recruited by Hannart and the remaining 25 percent came from employees, 80 percent of whom voluntarily decided to invest. The deal went through in July 2009.

With 46 of staff investing CHF 1.25 million, collectively, in their company, the effect could be felt across the entire staff. Hannart found himself in meetings explaining multiple times the difference between cash flow and profits, the terms of EBITA, the concept of leverage and many other financial concepts that were new to his mostly technically trained staff. With newly found independence, Selectron continued to grow. Strong business results allowed the company to quickly pay off the bank loans from the leverage buyout. ${ }^{35}$
\end{abstract}

The Selectron experience serves as an example that technically trained employees with little formal business background can be motivated to assume considerable business acumen.

\title{
Leveraging "Swissness"
}

Swissness turned out to be one of the few hotly debated subjects in many of the interviews. The cause of the controversy was created by a new regulation passed by the Swiss government, concerning the right to use the designation Swiss, which had been put into effect in 2017. This new regulation effected trademark protection and the right to use the coat of arms of Switzerland.

Since most of the SMEs documented here were producers of industrial products, the change in regulation affected many of these companies directly. The new regulation in effect required that, for a company to use the Swiss label and coat of arms, at least 60 percent of the cost, including R\&D costs, had to be realized in Switzerland. In addition, the process stage that conferred the product its essential characteristics also had to take place in Switzerland. Exceptions were granted for raw materials or semi-finished products not available in Switzerland. ${ }^{36}$

Swiss SMEs considered the use of the Swiss label to be a competitive advantage because it conveyed a combination of quality, precision, competence, and reliability to customers worldwide; it also helped justify a premium price dictated by higher operating costs incurred in the country.

\footnotetext{
${ }^{35}$ Adapted from Selectron company profile.

${ }^{36}$ SME portal for small- and medium-sized enterprises. Swiss Confederation www.kmu.admin.ch. Accessed February 2, 2020.
} 
For companies which relied heavily on Swiss manufacturing, the change did not require a change in strategy. Medartis, with complete production in Switzerland, could continue to rely on Swiss Made. So did Thermoplan, producer of automated coffee machines; Jura, the maker of home espresso machines; Felco, producer of pruning shears; and DC Swiss. Caran d'Ache, with its existing production near the French border, took the regulation into consideration for its relocation to preserve the Swiss label.

When the original Caran d'Ache site in central Geneva, where the company had been located since its creation, became too small for the growing business, a new site was developed in 1974 in Thônex at the edge of the city of Geneva. However, the area around the complex developed into a residential area, making it increasingly difficult for the transportation and delivery activity of about 20 trucks daily. The company was therefore planning to relocate to yet another site in Geneva that offered space for future expansion. Caran d'Ache was committed to remain and produce in Switzerland, eliminating the option of moving across the border into nearby France. The label Made in Switzerland required a Swiss production site. ${ }^{37}$

Felchlin, producer of chocolate specialties for the pastry trade, was also subject to the Swissness regulation governing food companies, where imports for foodstuff not available in Switzerland, such as cocoa beans, where excluded from the local valueadded regulation.

In its international marketing activities, Felchlin was able to exploit Swissness as it met the 60 percent limit for value-added in Switzerland. In its publications, the company did not see a need to display much of the Swiss flag. Word about Felchlin was also spread by a small group of key account managers located in Dubai, India and North America who worked with key customers in the roles of Felchlin ambassadors. ${ }^{38}$

For SMEs who could not measure up to the 60 percent Swiss content requirement, changes in the Swiss claim were required. For a company such as Sylvac, the use of non-Swiss caliper blanks resulted in the loss of the full Swiss made label. The same issue was requiring changes at Rüeger.

The debate about what constituted Swiss Made was of considerable importance to Kuhn Rikon.

After Kuhn Rikon in-sourced products from outside of Switzerland, the products could no longer be claimed to be Swiss Made, and the company, after several false starts, moved towards a differentiated labeling of its product line. The cookware made entirely in its Rikon factory continued to be labeled as Swiss Made and the use of the Swiss flag was authorized. The company's kitchen gadget and utensil line could no longer be sold under that label, even if it were brought back to Switzerland and packaged there. Like other firms, Kuhn Rikon changed to label its products as Swiss Designed, but had to forego the use of the Swiss flag on its packaging. ${ }^{39}$

\footnotetext{
${ }^{37}$ Adapted from Caran d'Ache company profile.

${ }^{38}$ Adapted from Max Felchlin company profile.

${ }^{39}$ Adapted from Kuhn Rikon company profile.
} 
The change in definition of Swissness forced several SMEs to change their reliance on Swiss Made to adopt other forms of Swissness. Similar to Kuhn Rikon using the term Swiss Designed, Burckhardt Compression and Sécheron used the term Swiss Engineered. For customers of both of these engineering firms, it was an important feature that final assembly of the equipment took place in Switzerland, so that the effective term was then a form of Swiss Assembled (authors' terminology), or in the case of LEM, the use of Swiss Company was sufficient for the customer base. The change in the legislation about the use of Swiss Made had unleashed a large number of variations in how Swissness could be leveraged.

\section{Leveraging Industry Clusters}

The value of industry clusters in developing competitiveness for their members was brought to the attention of strategists by Michael Porter and his research. ${ }^{40}$ According to the cluster concept, companies can benefit from the presence of similar firms in close proximity. Potential cluster benefits were discussed with some of the SMEs in the interviews.

Both FISBA and Mikrop, active in the optics industry and located in the St. Gallen area, commented positively on their cluster experience.

FISBA could benefit from a strong industry cluster in optics and photonics which had emerged after WW II. The pioneer companies were Wild Heerbrugg and Balzers, both established in the Rhine Valley. Several other optics manufacturers were later also launched in the region, including Leica Geosystems, FISBA, SwissOptic, Vectronix (later acquired by Safran), Zünd Precision Optics and Mikrop, thereby giving rise to a broad, diversified cluster. Technical high schools and R\&D centers like Rhysearch and CSEM contributed to technology transfer and to the success of the cluster.

The photonics and optical engineering companies in Switzerland collaborated in terms of sharing market data, industry information and ideas. The players in the industry established a study program in optics and photonics and were connected through a photonics department at SWISSMEM, the Swiss Association of Mechanical and Electrical Engineering Industries. Additional synergies were generated by rotating apprenticeship programs affording apprentices the opportunity to work for different photonics companies. ${ }^{41}$

Most of the companies interviewed were not part of a closely organized cluster along the lines of this optical cluster. However, some companies were part of a long industrial tradition in given industry sectors and thus benefited indirectly from the presence of other firms. These informal clusters benefited the companies in different ways.

\footnotetext{
${ }^{40}$ Porter, ME (1998) Clusters and the new economics of competition. Harvard Business Review 76 (6): 77 and Porter, ME (1990) The competitive advantage of nations. The Free Press, New York.

${ }^{41}$ Adapted from FISBA company profile.
} 
A textile industry cluster would include Lantal and Sefar, two companies in this sample, together with many other firms and machinery producers with a long tradition in Eastern Switzerland. The decline of the textile industry also made underutilized properties available for new companies, such as Filtrox.

- Indirectly, Felchlin benefited from a long tradition for chocolate production in Switzerland.

- A Swiss coffee machine cluster included both Thermoplan and Jura, in addition to other Swiss producers not covered by this research, such as Franke, Schaerer, and Frismag/Eugster.

- Part of a large cluster of automotive component suppliers included Oetiker, Komax, and u-blox.

- A strong and traditional railways and transport cluster included EAO, Sécheron, LEM, and Plumettaz.

- Part of a large Swiss life sciences cluster was Bachem and Geistlich. A Medtech cluster included Medartis and $\mathbf{C}+\mathbf{M}$.

- The microelectronic cluster included Rüeger and Sylvac.

- A chemtech cluster included Burckhardt Compression.

In some cases, firms also profited from the presence of companies from completely different industries, located nearby, which have also been covered in this analysis (see the example of Lantal working together with maxon).

Although this research excluded companies from the watch industry, it could document connections and the origins of a number of firms which greatly benefited from the presence of the large watch industry cluster, such as LNS, DC Swiss, Sylvac, C+M, and Acutronic.

Equally, many companies in the research sample leveraged an extensive presence of skilled parts manufacturers in the plastic or metal industries providing precision components, such as for EAO, Thermoplan, or Jura.

\section{Swiss Framework Conditions}

Swiss SMEs, operating from what is certainly one of the highest cost countries in the world, have learned to leverage the best of what is available from the local business environment. High cost is turned around into a premium strategy. A highly skilled labor force pool, combined with the dominant dual educational system, is leveraged to provide the human resources needed to run a premium market strategy. The presence of various industry clusters found for almost every conceivable industry sector creates an advantage in terms of gleaning additional benefits to strengthen a firms' competitiveness. And, last but not least, the image of Switzerland is leveraged to support the high-quality image of their products.

For Swiss SMEs, utilizing all of these framework conditions provides a substantial boost to a firm's competitiveness in global export markets. The benefit of these 
conditions does not accrue automatically, and the Swiss SMEs have become experts in the leveraging game.

Open Access This chapter is licensed under the terms of the Creative Commons Attribution 4.0 International License (http://creativecommons.org/licenses/by/4.0/), which permits use, sharing, adaptation, distribution and reproduction in any medium or format, as long as you give appropriate credit to the original author(s) and the source, provide a link to the Creative Commons license and indicate if changes were made.

The images or other third party material in this chapter are included in the chapter's Creative Commons license, unless indicated otherwise in a credit line to the material. If material is not included in the chapter's Creative Commons license and your intended use is not permitted by statutory regulation or exceeds the permitted use, you will need to obtain permission directly from the copyright holder.

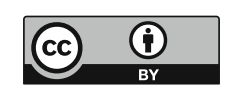

